\title{
A DESPLASTIFICAÇÃO DO CORPO EM ENUNCIADOS MIDIÁTICOS: DISCURSOS SOBRE MULHERES QUE FIZERAM EXPLANTES DE SILICONE
}

\author{
THE DEPLASTIFICATION OF THE BODY IN MEDIA \\ STATEMENTS: DISCOURSE ABOUT WOMEN WHO MADE \\ SILICONE EXPLANTS
}

Claudemir Sousa ${ }^{1}$

\begin{abstract}
Resumo: Neste artigo, analisamos enunciados nos quais a desplastificação do corpo é discursivizada como signo de felicidade, saúde e bem-estar. Para tanto, montamos um corpus com enunciados veiculados nas mídias digitais que tratam da realização de explantes por mulheres que tiveram complicações na saúde em decorrência da utilização de próteses de silicone nos seios. O aporte teórico-metodológico que ancora essa discussão repousa nos Estudos Discursivos Foucaultianos, assentado na proposta de análise enunciativa de Michel Foucault, a qual nos possibilita empreender uma investigação com base nos princípios de regularidade, dispersão, raridade e campo associado entre enunciados. Conclui-se que, no domínio discursivo das mídias digitais aqui analisado, a desplastificação do corpo inverte a ordem do discurso de que a remodelação do corpo é sinônimo de felicidade e impele mulheres a aceitarem o seu corpo como forma de garantir sua saúde, felicidade e bem-estar.
\end{abstract}

Palavras-Chave: Discurso. Mídia. Corpo. Governamentalidade.

\begin{abstract}
In this article, we analyze statements in which the deplastification of the body is discursivized as a sign of happiness, health and well-being. To this end, we set up a corpus with statements published in digital media that deal with the realization of explants by women who had health complications due to the use of silicone prostheses in the breasts. The theoretical-methodological support that anchors this discussion rests on Foucault's Discursive Studies, based on Michel Foucault's enunciative analysis proposal, which allows us to undertake an investigation based on the principles of regularity, dispersion, rarity and associated field between statements. We concluded that, in the discursive domain of digital media analyzed here, the deplastification of the body inverts the order of the discourse in which the remodeling of the body is synonymous of happiness and impels women to accept their body as a way of guaranteeing their health, happiness and well-being.
\end{abstract}

Keywords: Discourse. Media. Body. Governmentality.

\footnotetext{
${ }^{1}$ Doutor em Linguística e Língua Portuguesa. Professor do Instituto Federal de Educação, Ciência e Tecnologia do Maranhão (IFMA). E-mail: claudemir201089@ @otmail.com.
} 


\title{
Introdução
}

\begin{abstract}
Retirar a prótese foi maravilhoso: nada dolorido, não tomei remédio para dor e no dia seguinte já estava caminhando.

Faz quase 3 meses que não tomo um remédio para nada e meus sintomas sumiram. A minha autoestima voltou. Hoje me olho no espelho e me sinto maravilhosa. Meu corpo está super proporcional, não sinto mais aquele peso, incômodo, dores, a minha fisionomia é outra, minha vida é outra, eu estou extremamente feliz (DJEHDIAN, 2021, online).
\end{abstract}

O enunciado precedente é um excerto de uma matéria publicada no portal de notícias UOL e consiste em uma fala atribuída a Amanda Djehdian, de 34 anos, identificada como uma empresária, ex-BBB (ela participou do reality show televisivo Big Brother Brasil) e criadora de conteúdo digital. O objeto de discurso do qual ele se ocupa é a realização de cirurgia para retirada de próteses de silicone nos seios, procedimento denominado de explante, por mulheres que alegam sentir problemas de saúde em decorrência dos efeitos colaterais dessa plastificação do corpo.

Nesse enunciado, o sujeito mulher que exerce a modalidade enunciativa (FOUCAULT, 2008) inverte a ordem do discurso (idem, 2007) em que a plastificação do corpo é associada a beleza, bem-estar e felicidade, concebendo-a como um risco à saúde. Nesse sentido, o explante preenche um espaço discursivo que é o da saúde, bem-estar, autoestima e felicidade, anteriormente atribuído ao implante.

Essa prática de retirada dos implantes de silicone nos seios passou a ser discursivizada em diversas mídias após mulheres compartilharem nas redes sociais os sintomas que estavam apresentando, alegando ser em decorrência das próteses de silicone. Com isso, foram criados perfis, como as contas da rede social Instagram @ perigos.do.silicone e @explantedesilicone, para conectar essas mulheres e orientar sobre soluções possíveis para os sintomas comuns apresentados por elas.

Algumas alegam que, ao compartilhar com médicos que estavam sentindo determinados sintomas e que muitas mulheres sentiam os mesmos e paravam de sentir após a retirada das próteses, ouviam deles que não existem evidências científicas de que as próteses de silicone podem estar causando os danos à saúde por elas relatados.

Assim, ao enunciar da posição de representante da Associação Brasileira de Cirurgia Plástica, O cirurgião plástico Leandro Pereira, que é secretário geral dessa 
associação, reafirma esse posicionamento do saber médico-estético de negar a existência de uma "doença do silicone", como segue:

\begin{abstract}
A retirada das mamas é algo que está ganhando força recentemente, mas o número ainda é pequeno e não sabemos dizer se é algo comportamental ou de indicação médica efetiva. Pensamos muito em silicone como uma cirurgia estética, mas temos que considerar reconstruções de mama, mastectomia, grandes assimetrias.

Não funciona como tirar um aplique de cabelo. Tem que ser estudada, desenhada, pensada. Analisar se precisamos tirar só a próteses, se há necessidade de mamoplastia associada, se é necessário tirar mais do que a prótese. Temos que estudar todo o problema e propor a melhor solução para resolvê-lo (PEREIRA, 2021, online).
\end{abstract}

Nesse enunciado, o sujeito que enuncia se posiciona no interior de uma instituição que lhe credibiliza saberes e poderes para determinar o grau de segurança dos implantes e isentá-los da ocorrência de possíveis enfermidades. Trata-se da mobilização do discurso em um jogo de esquiva (FOUCAULT, 2002). Além disso, a ordem do discurso (idem, 2007) econômico é um obstáculo para a consecução de uma possível retirada das próteses, por esse procedimento requerer uma preparação e avaliação de necessidades.

Assim, esses enunciados evidenciam uma luta discursiva polêmica e estratégica (FOUCAULT, 2002) no interior do inapreensível arquivo (idem, 2008) que trata do corpo da mulher nas sociedades ocidentais, nos quais os seios femininos são símbolos sexuais. Como os discursos estão sujeitos às leis da regularidade (FOUCAULT, 2008), que implica, entre outras coisas, transformações nos regimes de verdade (FOUCAULT, 2013a), ou seja, no que é verdadeiro em certo tempo e espaço, no domínio discursivo da estética corporal se pode perceber que os seios que são valorizados são os firmes, empinados, fartos, aos quais se agregam os sentidos de beleza e juventude.

Mas essa ordem discursiva da estética corporal parece estar sendo tencionada pela ordem do discurso (FOUCAULT, 2007) da saúde da população, na medida em que as mulheres autodenominadas "explantadas" estão pondo em discurso uma valorização dos próprios seios como eram antes: pequenos e flácidos. É na busca de segurança, saúde e bem-estar que repousa esse novo sentimento de beleza corporal.

Assim, neste artigo, trataremos dos casos de realização de explante de silicone por mulheres que alegam apresentar problemas em seu corpo em virtude das próteses. Para tanto, analisaremos enunciados das mídias digitais que veiculam discursos sobre a saúde, a felicidade e o bem-estar associados à realização desse procedimento cirúrgico. 
Para analisarmos o corpus, buscaremos suporte na arqueogenealogia de Michel Foucault, concebida, aqui, como um aporte teórico-metodológico que ancora o campo denominado por pesquisadores brasileiros de "Estudos Discursivos Foucaultianos". Trata-se de uma proposta de análise enunciativa do discurso que nos possibilita empreender uma investigação com base nos princípios de regularidade, dispersão, raridade e campo associado entre enunciados (FOUCAULT, 2008). Isso significa perseguir as semelhanças e diferenças entre enunciados, sua forma de agrupamento, a singularidade de sua existência e sua presença em um domínio de outros enunciados.

A abordagem que adotaremos será a transcrição de falas das mulheres presentes duas matérias jornalísticas veiculadas no portal de notícias UOL, orientando-nos pelos princípios foucaultianos anteriormente explicados. Além disso, apresentaremos uma imagem que acompanha a primeira matéria a ser analisada, por se tratar de uma celebridade, e não apresentaremos as demais, de anônimas, por questão de ética.

Assim, descreveremos a maneira como este artigo está organizado. Na seção seguinte, discutiremos o aporte teórico de Foucault e seus interlocutores para tratarmos do corpo. Em seguida, faremos uma incursão histórica pela prática de implante de silicone. Finalmente, analisaremos os enunciados que tratam da realização de explantes por mulheres e traremos as considerações finais.

\section{O corpo como enunciado para análise discursiva: contribuições de Michel Foucault}

A análise de discurso que empreendemos dialoga com o projeto arqueogenealógico de Foucault (2002, p. 9), para o qual os fatos discursivos possuem um aspecto linguístico, mas devem ser tomados “como jogos (games), jogos estratégicos, de ação e reação, de pergunta e resposta, de dominação e de esquiva, como também de luta".

Esse autor empreende uma análise do discurso "como jogo estratégico e polêmico" (idem), o que configura um princípio metodológico. Para ele, o sujeito é o alvo das relações de saber-poder nas quais são construídos os modelos de subjetividade.

Nesse sentido, Foucault (2013a) considera que o corpo é o centro dessas formas de lutas discursivas e das relações de saber-poder. Por essa razão, ele propõe que a genealogia, como tática de análise que se articula ao método arqueológico, entrelaça o corpo e a história e "deve mostrar o corpo inteiramente marcado de história e a história 
arruinando o corpo" (FOUCAULT, 2013b, p. 65), afinal, o corpo contemporâneo é resultado de fabricações feitas por saberes, poderes e formas de resistência dos sujeitos.

O conceito de corpo vem sendo explorado em análise do discurso (AD) no Brasil há alguns anos. As referências para conduzir essas pesquisas são buscadas nos campos da filosofia, história, antropologia, psicanálise, artes, dentre outras. A exemplo, vamos citar os estudos de três pesquisadores que se dedicaram a pesar esse tema na análise do discurso: Ferreira (2013), Courtine (2011; 2013) e Milanez (2009).

Ferreira (2013) é uma das pesquisadoras da AD no Brasil que situa suas discussões acerca do corpo como objeto discursivo no entrecruzamento das teorizações de Pêcheux com autores de diferentes abordagens teóricas, como Marcel Mauss, Freud, Lacan, Paul Schielder, Didier Anzieu e Foucault. Ao mobilizar conceitos de Pêcheux para tratar do corpo, essa autora se distancia de muitos interlocutores desse autor francês, que se debruçam majoritariamente em outras de suas noções.

Assim, as discussões de Ferreira (2013) entrelaçam concepções desenvolvidas por Pêcheux, fundador da disciplina de análise do discurso no campo da linguagem, com a antropologia, a psicanálise e a filosofia. Na concepção dessa autora, para a AD,

Mais do que objeto teórico o corpo comparece como dispositivo de visualização, como modo de ver o sujeito, suas circunstâncias, sua historicidade e a cultura que o constituem. Trata-se do corpo que olha e que se expõe ao olhar do outro. O corpo intangível e o corpo que se deixa manipular. O corpo como lugar do visível e do invisível (FERREIRA, 2013, p. 78).

O corpo discursivo de que essa autora fala é aquele investigado como um objeto material construído pelo discurso. O que se estuda, portanto, são as materialidades discursivas do corpo enquanto objeto constituído pela linguagem, atravessado pela história. A análise dessa materialidade serve para observar o sujeito.

Courtine (2011), por seu turno, se interroga sobre como o corpo se tornou um objeto de investigação histórica. Em sua concepção, o corpo enquanto objeto teórico é uma invenção do século XX, remontando às investigações de Freud, Husserl, MerleauPonty, Mauss e Foucault. Embasado em Foucault, Courtine (2011) investiga as mutações do olhar sobre o corpo em uma cultura visual, na qual o corpo é penetrado, observado, exposto, inclusive em seus aspectos mais íntimos e sexuais.

Já Milanez (2009) esclarece que se interessa pelo corpo como unidade discursiva não restrito às suas funções do cotidiano, mas atrelado às representações pelas quais o identificamos. Trata-se de considerar o corpo como uma prática discursiva, que possui 
existência material e histórica. Corpo-enunciado, como pensado por Foucault (2008), inscrito em redes, possibilitando deslocamentos, formação de saberes e tipos de sujeitos.

Parece consenso entre Ferreira (2013) Courtine (2011) e Milanez (2009) que foi nos trabalhos de Foucault que o corpo ganhou seu título de nobreza. A contribuição de Foucault é tratar do corpo como artefato teórico e também prático, presente nas lutas de mulheres, homossexuais e doentes mentais por liberdade, e também inscrever as coerções que se exercem sobre o corpo "no horizonte de longa duração" (COURTINE, 2013, p. 17).

Nesse construto teórico, o corpo é uma realidade biopolítica e histórica, sujeito às transformações espaço-temporais. O corpo, para Foucault, está ligado a práticas de saber, de poder e de subjetivação. A título de clareza, iremos conceituar biopoder, biopolítica e governamentalidade a partir das discussões de Foucault $(2005 ; 2013 \mathrm{c})$, visto que esses conceitos estão atrelados à sua maneira de tratar o corpo e serão retomados nas análises.

Primeiramente, o conceito de biopoder é compreendido por Foucault (2005, p. 294, grifos do autor) como uma 'tecnologia do poder sobre a 'população' enquanto tal, sobre o homem enquanto ser vivo, um poder continuo, cientifico, que é o poder de 'fazer viver"”. A forma de exercício desse poder, de maneira sutil, é o que se denomina biopolítica da espécie humana, concebida por Foucault (2005, p. 289-290) como uma tecnologia de poder na qual se tata de "um conjunto de processos como a proporção dos nascimentos e dos óbitos, a taxa de reprodução, a fecundidade de uma população, etc.”, os quais, aliados às preocupações econômicas e políticas, constituem os objetos de saber e os alvos de controle dessa tecnologia de poder. Ela lança mão de medições estatísticas, observações e intervenções nos fenômenos concernentes à população.

Para tanto, introduz-se uma medicina que vai exercer um papel de higiene da população, normalização do saber e medicalização da população. Em nossa compreensão, a realização das cirurgias plásticas para implante e explante de silicone se insere nas estratégias do biopoder e da biopolítica, na medida em que atenta às informações dos saberes médicos, segue normas de higiene, para evitar adoecimento. Tais procedimentos devem ocorrer nas instituições adequadas, conforme as designações da biopolítica.

Finalmente, a noção de governamentalidade (FOUCAULT, 2013c) consiste nas instituições, procedimentos, análises e reflexões, cálculos e táticas que permitem exerce o biopoder e a biopolítica. Foucault (2013c) compreende o governo como múltiplas formas de condução, de ação sobre alguma coisa. Com isso, pode-se fala em um exercício de formas de governo que articulam formas de conduzir a si e ao outro. Tal forma de 
governo tem como alvo a população e utiliza como instrumento os dispositivos de segurança, que são os instrumentos pelos quais se garante o bem-estar da população.

É com base nesse referencial teórico que iremos analisar a relação do sujeito com o seu corpo na contemporaneidade a partir de enunciados que tratam da realização de explante por mulheres para se sentirem mais saudáveis. Antes, uma imersão histórica nas práticas de implante de silicone nos seios se faz necessária.

\section{Arqueogenealogia do silicone para fins estéticos}

O silicone é empregado para diversas finalidades, como industrial, comercial e estética. Por essa razão, ele apresenta diferentes variações em sua forma e consistência. Neste artigo, interessa-nos a sua utilização para fins estéticos. Nesse caso, o produto é a matéria prima para próteses e implantes não líquidos, constituindo-se no tipo de cirurgia plástica mais comum entre as mulheres no Brasil. Em segundo lugar está a redução dos seios (segundo Nascimento (2011), este tipo de cirurgia era mais comum até os anos de 1980) e, em seguida, vem a lipoaspiração, seguida pela rinoplastia. No caso dos homens, a rinoplastia é a principal, seguida da redução das mamas e depois a lipoaspiração.

A utilização de silicone, no Brasil, deve estar sujeita às normas sanitárias da Agência Nacional de Vigilância Sanitária (ANVISA), que determina quem exerce o saber e o poder para manipulá-lo e sob quais condições do espaço clínico isso pode ocorrer. Além disso, as próteses que são importadas são avaliadas pelo Instituto Nacional de Metrologia, Qualidade e Tecnologia (INMETRO), que realiza testes de qualidade e emite um selo de aprovação.

O uso de silicone para fins estéticos teve início no hospital Jefferson Davis, em Houston, no Estado do Texas, nos Estados Unidos da América (EUA), em 1962, quando Timmie Jean Lindsey, mãe de seis filhos, realizou um implante para aumentar o tamanho dos seios, sob a ação dos cirurgiões Frank Gerow e Thomas Cronin. Na ocasião, ela foi ao hospital para retirar uma tatuagem nos seios e os médicos lhe ofereceram a possibilidade de participar do implante de silicone pioneiro.

No ano seguinte, o resultado foi apresentado à Sociedade Internacional de Cirurgias Plásticas. As condições para que a cirurgia fosse um sucesso de procuras estavam já implantadas: a utilização de sutiãs com enchimento, a popularidade dos artigos 
de plástico no pós-guerra, as referências estéticas das atrizes de Hollywood, os corpos femininos veiculados na revista Playboy e o ideal estético da boneca Barbie.

Os implantes de silicone se tornaram fenômeno característico das atrizes de filme pornô nos Estados Unidos e uma "norma para as atrizes de Hollywood e, posteriormente, para as donas-de-casa norte-americanas" (NASCIMENTO, 2011, p. 5).

Uma versão sobre a utilização de silicones antes da primeira cirurgia conta que prostitutas japonesas injetavam silicone roubado no porto de Yokohama nos seis para atraírem os soldados dos Estados Unidos durante a ocupação no pós-guerra, o que acarretava gangrena na área ao redor dos seios. Já no espaço clínico, com o tempo, algumas inovações foram feitas no procedimento de implante, como a diversificação nos tamanhos, modernização dos modelos e uso de imagem 3D. A mudança na consistência mais gelatinosa tornou as rupturas das próteses mais raras.

Ainda hoje, a utilização dessas próteses é atravessada de polêmicas. Para algumas mulheres, incluindo Timmie Jean Lindsey, ela traz benefícios, como consta na sua fala a seguir: "eu achei que eles tinham ficado perfeitos (...). Eu os sentia tão macios, igual a seios de verdade (...). Mas só me dei conta do resultado mesmo quando saí na rua e percebi que os homens assobiavam para mim” (BOWES \& HEBBLETHWAITE, 2013, online).

Para outras mulheres, há um arrependimento em decorrência dos prejuízos que acreditam trazer à sua saúde, como mostraremos adiante ao analisarmos as falas das mulheres explantadas presentes em enunciados das mídias digitais.

Nos anos de 1990 os saberes médico-científicos já apontavam para riscos de o material do silicone causar danos ao sistema imune. Em 1992, a agência reguladora de alimentos e drogas nos Estados Unidos (Food and Drug Administrations) limitou os implantes de silicone, pois havia a realização de 400 cirurgias em mulheres por dia (NASCIMENTO, 2011). Com o tempo, o implante de silicones foi banido nos Estados Unidos e, posteriormente, retomado com padrões de segurança. Já em 2010, vários países proibiram a comercialização de próteses da empresa francesa Poly Implant Protheses, por conter silicone industrial, que pode causar câncer, e apresentar risco de se romper.

Atualmente, percebe-se um embate discursivo, que se apresenta como um jogo polêmico e estratégico (FOUCAULT, 2002), entre cirurgiões plásticos e mulheres que realizaram implantes de silicone, visto que muitas delas alegam apresentarem problemas de saúde em decorrência dos implantes de silicone, ao passo que o saber médico-estético refuta essa possibilidade e advoga em defesa da segurança das próteses de silicone. 
$\mathrm{Na}$ atualidade, os seios que são valorizados nas sociedades ocidentais continuam a ser os firmes, empinados e fartos, os quais estão associados a beleza e juventude. Porém, Nascimento (2011) afirma ser possível encontrar sociedades que desviam desses padrões de beleza do ocidente, ao valorizar seios caídos e flácidos. Trata-se, portanto de um aspecto discursivo socialmente construído, mas passível de mutações, na medida em que, na atualidade, os meios de comunicação também vêm taxando os seios fartos e siliconados como deselegantes, cafonas e vulgares e alertando para riscos à saúde.

A realização de cirurgias plásticas nos seios femininos tem diferentes finalidades. Por um lado, constitui um procedimento para seguir uma moda. De acordo com Nascimento (2011, p. 2, grifos da autora):

a censura da beleza pode fazer com que qualquer mulher acredite que apenas os seus seios são flácidos, caídos, grandes ou pequenos demais, esquisitos ou decididamente errados, feios. A partir da comparação dos seus seios com os seios "ideais", mulheres de todas as idades podem desenvolver uma fixação quanto à "firmeza" e a "boa forma" dos seios, incluindo, aí, o seu tamanho.

Nesse sentido, o implante de silicones nos seios com finalidades estéticas é um imperativo que resulta da censura ao corpo não oficial e impele mulheres a conseguirem os seios perfeitos da moda. Nesse processo de cesura do corpo, os seios perdem o sentido de maternidade e também ocupam um espaço de feminilidade e beleza que alguns enunciados que circulam sobre a mulher brasileira atribuem às nádegas como a parte representativa da sua beleza, afirmando, ou negando, como o faz a cantora Rita Lee na música "Pagu", de sua composição, que diz: "Nem toda brasileira é bunda/ Meu peito não é de silicone".

Por outro lado, há mulheres que fazem tal procedimento para corrigir cirurgias realizadas para retirar as mamas em virtude do câncer de mama, ou mesmo para prevenir esse acometimento, como o fez a atriz norte-americana Angelina Jolie. Para essas mulheres e para outras inconformadas em medir seus seios em centímetros, os seios com implantes de silicone adquirem o sentido de saúde e autoestima.

Entretanto, os saberes científicos que compõem a biopolítica da espécie humana (FOUCAULT, 2005) apontam que os seios femininos são uma parte do corpo propensa a doenças e as cirurgias podem interferir na amamentação e na detecção de tumores em mamografias. 
A realização de cirurgias nos seios pode também estar relacionada à influência dos padrões de beleza da cultura norte-americana. Na contramão desse procedimento, há mulheres que realizam cirurgias para redução das mamas em busca de um outro padrão de beleza, o dos peitinhos, ou que realizam essas cirurgias de troca das próteses ou retirada dos silicones por questão de saúde, procedimento atualmente denominado de explante.

Dessa maneira, o explante emerge como um procedimento cirúrgico preventivo, embasado nos saberes científicos que constituem a biopolítica da população (FOUCAULT, 2005). As mulheres estão realizando esse procedimento por risco de ruptura das próteses ou por apresentarem problemas de saúde que atribuem aos implantes de silicone. Trata-se, assim, de uma prática de governo de si (idem, 2013c) manifesto no cuidado com o corpo que recorre às estratégias do biopoder, como discutiremos adiante.

\section{A desplastificação do corpo como estratégia de governo de si em enunciados de mulheres explantadas}

Em 28 de Fevereiro de 2021, uma reportagem veiculada no programa Fantástico, da Rede Globo de Televisão, mostrou que um grupo de mulheres brasileiras está fazendo um processo de retirada do implante de silicone nos seios após sentirem sintomas como mal-estar e queda de cabelo.

No dia seguinte, em 01 de março de 2021, foi veiculada uma matéria no portal de notícias UOL sobre esse mesmo fato, com foco em uma ex-participante de reality show, cuja manchete e imagem, com respectiva legenda da matéria, reproduzimos aqui.

Figura 1 - Ex-BBB Amanda retira silicone após doença: ‘sou outra mulher, sem dor'

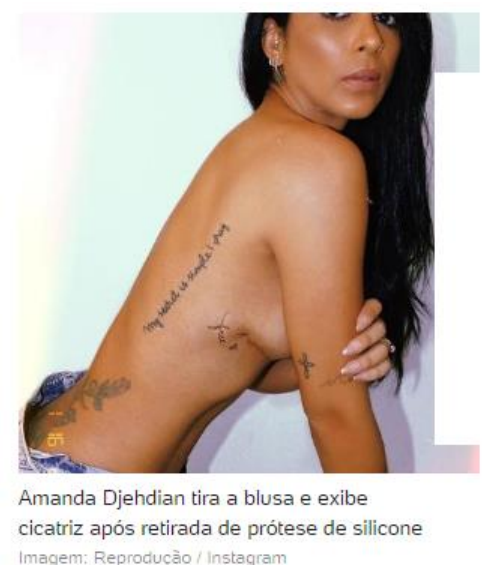

Ex-BBB Amanda retira silicone após doença: 'Sou outra mulher, sem dor'

Do UOL, em São Paulo 01/03/2021 11h28 Atualizada em 01/03/2021 11h28

Fonte: UOL 
Na matéria em questão, e em outra que mobilizamos para análise, há a exibição do corpo das mulheres que fizeram explantes, mas, por questão de ética, apresentamos somente essa. Corpos que se expõem ao olhar, deixam-se manipular e se constituem como o lugar do visível (FERREIRA, 2013). A circulação da imagem desses corpos em nossa cultura visual (COURTINE, 2011) e sua discursivização pela linguagem é o que o tornam objeto de análise para nós aqui, de modo a observar o sujeito mulher na atualidade.

Desse modo, nesse excerto de enunciado, o corpo de Amanda é exposto aos olhares dos internautas nas linhas de visibilidade (DELEUZE, 1996) do aparelho midiático como um corpo cicatrizado e desplastificado, fazendo emergir sentidos que tencionam a ordem do discurso (FOUCAULT, 2007) que veicula a plastificação do corpo da mulher à beleza e ao sentimento de felicidade.

O título da matéria traz também um excerto da fala de Amanda, em discurso direto, na qual ela se posiciona como um sujeito cuja corporeidade está ligada aos sentimentos em relação às transformações estéticas. Trata-se, agora de um corpo cujas dores decorreram da remodelação e são aplacadas por transformações que concorrem para a desplastificação.

Esse procedimento cirúrgico de retirada das próteses de silicone é denominado de explante, em sentido oposto ao procedimento de implante, e as mulheres lançam mão da subjetividade (ou identidade) de explantada para enunciarem a si, para posicionarem-se discursivamente acerca do seu corpo.

Em outro excerto da fala de Amanda para o programa Fantástico, da Globo, reproduzido pelo portal UOL, ela declara que "faz dois meses que não sinto dor alguma. Eu durmo, eu sou outra mulher. Meu corpo está se definindo por si só. Me sinto mais linda, mais feliz com os meus seios que voltaram a ser o tamanho que eram com meus 20 anos" (DJEHDIAN, 2021, online).

Além de recorrer aos sentidos de saúde, o sujeito enuncia acerca da beleza, da felicidade e da juventude, como se o que ela buscasse com a cirurgia fosse também uma espécie de regressão. Dessa forma, a desplastificação do corpo situa o sujeito que enuncia em um domínio do governo de si que concilia a estética com o fazer reviver (FOUCAULT, 2005).

O sujeito responsável por essa fala afirma ter ficado por mais de 15 anos com a prótese de silicone nos seios, movida por um imperativo estético em que os seios grandes e duros são tidos como belos na ordem do discurso (FOUCAULT, 2007) atual, mas que 
decidiu sair dessa ordem discursiva diante da possibilidade de finitude da vida. Há, portanto, uma oposição entre o fazer-se viver e o não se permitir morrer.

É, portanto, o estado de adoecimento e o medo de deixar-se morrer que faz com que esse sujeito-mulher ressignifique a plastificação do corpo por meio de um processo de explante. A felicidade, antes associada à transformação do corpo, passa a ser buscada na aceitação da sua imagem corporal anterior à cirurgia plástica e na saúde daí decorrente.

No dia 30 de março de 2021, outra matéria sobre esse objeto de discurso foi publicada pelo portal UOL, da qual retiramos o excerto que serve de epígrafe para esse texto. Nele, além do depoimento de Amanda, há as falas de outras mulheres com as quais o seu enunciado apresenta regularidades (FOUCAULT, 2008). Nesse conjunto de enunciados é possível perceber um jogo de repetições e transformações na relação da desplastificação do corpo com a saúde, conforme mostramos adiante.

Iniciamos pela fala de Evelyn Sotam, de 29 anos, que trabalha como arte educadora e bailarina. Ela declara o que segue:

\begin{abstract}
Decidi colocar a saúde em primeiro lugar, mas tirar a prótese é algo que mexe muito com a autoestima. Como eu ia me livrar de algo que coloquei para me sentir bem? Hoje consigo ver beleza em seios pequenos, mas era apaixonada pelos grandes. Precisei cuidar de mim (SOTAM, 2021, online).
\end{abstract}

Aqui, o sujeito mulher se enuncia como alguém que exerce um governo de si (FOUCAULT, 2013c) pela condução da sua vida no aspecto biológico em uma dualidade entre um procedimento estético para buscar autoestima e beleza e a reversão desse mesmo procedimento em busca de saúde. Para tanto, ela lança mão da elaboração de um novo regime de verdade (idem, 2013a) acerca do que seja bem-estar e beleza em um tipo de seios que antes era concebido como feio. É no interior do discurso, como espaço de polêmica e estratégia (idem, 2002) que ocorre essa tensão entre padrões estéticos e de saúde. É a linguagem que revela essa luta para elaborar formas de conduzir a própria vida com base nos princípios que regem a sociedade atual, como o bem-estar e a autoestima.

O governo de si emerge como o novo imperativo para esse sujeito mulher, que se insere na ordem do discurso (FOUCAULT, 2007) da biopolítica, o qual determina uma certa proibição de adoecer e de morrer, já que nas sociedades de normalização cada um exerce um biopoder (idem, 2005) sobre si mesmo. Esse poder ecoa no enunciado anterior como aquilo que impele o sujeito mulher que enuncia a aliar ao seu novo corpo os sentidos de beleza, autoestima, bem-estar e saúde para conduzir sua vida de forma bem governada. 
Esse enunciado possui regularidades com outro que a matéria traz, que é uma fala de Renata Zi Colconi, de 32 anos, a qual trabalha como design de joias. Ela fala sobre o seu pós-operatório e afirma o que segue:

\begin{abstract}
Tive melhoras assustadoras muito rapidamente. A primeira delas foi minha energia, que retornou. Eu desinchei, meu rosto mudou, minhas unhas cresceram, meu cabelo parou de cair, meu olho começou a ter brilho e minha visão embaçada melhorou.

A melhor parte foi que a minha sensibilidade voltou. Ela não está $100 \%$, mas depois de uns dois anos voltei a sentir estímulos na região. Ter meu corpo 'normal' de novo foi ótimo, uma sensação de liberdade que eu não imaginava que precisava (COLCONI, 2021, online, grifo do autor).
\end{abstract}

Nesse enunciado, as modalidades enunciativas (FOUCAULT, 2008) que emergem são de um sujeito que governa a si ao voltar a se reconhecer como biologicamente normal e livre. A retirada das próteses de silicone pelo processo de explante insere o corpo em uma norma concebida como estar saudável, com as características corporais anteriores, independente do sentimento de beleza. Há, pois, uma perseguição de outra norma, que não é a da estética, e sim a da saúde.

Aqui, a regularidade (FOUCAULT, 2008) se dá por uma transformação em relação aos enunciados anteriores, visto que o sujeito mulher não enuncia a partir de uma ordem da estética, lançando mão dos imperativos do governo de si, da condução de uma vida saudável, sem referência à beleza como resultado das transformações no corpo.

Ao mesmo tempo, o corpo é enunciado pelo próprio sujeito como um corpo arruinado de história (FOUCAULT, 2013b): atravessado por uma história de antes e depois da plastificação para implante de silicone. Um corpo que foi remodelado sob a égide do saber-poder médico-estético e precisou elaborar formas de resistência a esse mesmo domínio do saber-poder, visto que os discursos das mulheres explantadas não são acolhidos como verdadeiros nesse domínio, que se apresenta como científico e oficial.

Esse modo de enunciar o próprio corpo é semelhante ao que emerge no último enunciado que a matéria apresenta, uma fala de Diane Neubüser, identificada como jornalista, de 33 anos, a qual diz o que segue:

Eu já me senti melhor quando eu acordei da cirurgia. Eu estava descansada quando voltei da anestesia, como não me sentia há sete anos. Minhas olheiras tinham sumido, a cor da minha pele tinha voltado. Como se o problema tivesse sido tirado com a mão. Fiz a retirada em outubro de 2019 e desde então nunca mais tive nenhum sintoma (NEUBÜSER, 2021, online). 
De forma semelhante ao que ocorre no enunciado anterior, aqui, o sujeito mulher que enuncia também se inscreve na ordem do biopoder (FOUCAULT, 2005), ou seja, de um exercício de poder sobre a sua saúde, focando no aspecto biológico, sem fazer referências ao estético como fator principal para fazer a retirada das próteses de silicone.

Ela enuncia-se como um sujeito cujo corpo recupera as suas funções e aparências de um momento anterior no passado, deixando de apresentar os índices que apontam para uma possível enfermidade atribuída às próteses de silicone. É o próprio sujeito que elabora os cálculos e medições estatísticas acerca do seu corpo para compor a biopolítica da população, visto que seus discursos não são acolhidos como verdadeiros no domínio científico da cirurgia plástica.

Todos esses enunciados estabelecem um jogo polêmico e estratégico (FOUCAULT, 2002) com os enunciados do discurso médico-estético oficial, como apresentamos na introdução a partir da fala do cirurgião plástico Leandro Pereira, que afirma não existir comprovação de que os sintomas que essas mulheres apresentam e relatam sejam em decorrência dos implantes de silicone nos seios.

Ao não terem seus discursos acolhidos e legitimados como verdadeiros pela ordem do discurso (FOUCAULT, 2007) médico-estético, essas mulheres travam uma luta discursiva com o saber tido como oficial. Elas elaboram formas de se interconectarem em redes sociais para buscar uma vida saudável e ao mesmo tempo feliz e bela. Essas mídias servem como campo de batalha para corpos e discursos e é a linguagem que possibilita visualizar essas relações polêmicas e estratégicas entre saber, poder e subjetividade.

\section{Considerações finais}

Este artigo analisou os discursos sobre a desplastificação do corpo como sinônimo de felicidade, saúde e bem-estar presentes em enunciados das mídias digitais que apresentam falas de mulheres que realizaram um procedimento cirúrgico denominado de "explante" de silicone, sob a alegação de que estavam apresentando sintomas de uma doença ainda não reconhecida pela comunidade científica de cirurgiões plásticos.

Os enunciados nos possibilitaram concluir que as mulheres explantadas travam uma luta discursiva com o saber-poder médico-estético e as redes sociais foram utilizadas como o campo de batalha para que elas pudessem elaborar um novo regime de verdade sobre os implantes de silicone e sobre o seu corpo. 
Nesse jogo polêmico e estratégico, o corpo é o centro da luta, visto que o saberpoder dos cirurgiões plásticos é confrontado pela exposição dos corpos cicatrizados e desplastificados das mulheres explantadas, as quais são inseridas em uma nova ordem discursiva, instando a si mesmas a aceitarem seus corpos como maneira de garantir saúde, felicidade e bem-estar.

\section{Referências}

ANGELINA Jolie anuncia ter retirado seios para evitar câncer. $B B C N E W S, 14$ de maio de 2013. Brasil. Disponível em: https://www.bbc.com/portuguese/noticias/2013/05/130514_angelina_jolie_retirada_seio s_rw\#: :text=A\%20atriz\%20Angelina\%20Jolie\%20anunciou, americano\%20The\%20N ew\%20York\%20Times. Último acesso em: 31 mar. 2021.

COURTINE, Jean-Jacques. Introdução. In: COBIN, Alain; COUTINE, Jean-Jacques; VIGARELLO, Georges (Orgs.). História do Corpo: as mutações do olhar: o século XX. Trad. Ephraim Ferreira Alves. 4. ed. Rio de Janeiro: Vozes, 2011, p. 7-13.

Corpo, discurso, imagens - Entrevistas. In: COURTINE, Jean-Jacques. Decifrar o corpo: pensar com Foucault. Trad. Francisco Morás. Petrópolis, RJ: Vozes, 2013, p. 11-46.

DELEUZE, Gilles. O que é um dispositivo? In: DELEUZE, Gilles. O mistério de Ariana. Trad. Edmundo Cordeiro. Lisboa, PT: Ed. Vega/passagens, 1996.

Ex-BBB Amanda retira silicone após doença: 'sou outra mulher, sem dor'. $U O L, 01$ de março de 2021. Disponível em: https://tvefamosos.uol.com.br/noticias/redacao/2021/03/01/ex-bbb-amanda-protesesilicone.htm. Último acesso em: 31 mar. 2021.

FERREIRA, Maria Cristina Leandro. O corpo como materialidade discursiva. REDISCO, v. 2, n. 1, p. 77-82, 2013.

FOUCAULT, Michel. A verdade e as formas jurídicas. Trad. Roberto Cabral de Melo Machado e Eduardo Jardim Moais. 3. ed. Rio de Janeiro: NAU Editora, 2002.

Aula de 17 de maço de 1976. In: FOUCAULT, M. Em defesa da sociedade: Curso no Collège de France (1975-1976). Trad. Maria Ermantina Galvão. 4. ed. São Paulo: Martins Fontes, 2005, p. 285-315.

A ordem do discurso. Trad. Laura Fraga de Almeida Sampaio. 15. ed. São Paulo: Edições Loyola, 2007.

A arqueologia do sabe. Trad. Luiz Felipe Baeta Neves. 7. ed. Rio de Janeiro: Forense Universitária, 2008. 
Verdade e poder. In: FOUCAULT, Michel. Microfísica do poder. Trad. Roberto Cabral de Melo Machado. 26. ed. São Paulo: Graal, 2013a, p. 35-54.

Nietzsche, a genealogia e a história. In: FOUCAULT, Michel. Microfísica do poder. Trad. Roberto Cabral de Melo Machado. 26. ed. São Paulo: Graal, 2013b, p. 5586.

A governamentalidade. In: FOUCAULT, Michel. Microfísica do poder. Trad. Roberto Cabral de Melo Machado. 26. ed. São Paulo: Graal, 2013c, p. 407-431.

MILANEZ, Nilton. Corpo cheiroso, corpo gostoso: unidades corporais do sujeito no discurso. Acta Scientiarum Language and Culture, v. 31, n. 2, p. 215-222, 2009.

NASCIMENTO, Josilene Barbosa do. Quando os seios não pertencem às mulheres: a moda das mulheres siliconadas e sua previsão de desconstrução. III Seminário Nacional Gênero e Práticas Culturais: Olhares diversos sobre a diferença. João Pessoa: 2011, p. $1-11$.

POLO, Rafaela. De peito aberto. UOL, 31 de março de 2021. Disponível em: https://www.uol.com.br/universa/reportagens-especiais/explante-de-silicone/\#page3.

Último acesso em: 31 mar. 2021.

RODRIGUES, Fenando. As 8 cirurgias estéticas mais populares em homens e mulheres 2016. Dr Fernando Rodrigues Cirurgião Plástico, 28 de dezembro de 2020. Disponível em: $\quad$ https://drfernandorodrigues.com.br/8-cirurgias-esteticas-maispopulares/\#: :text=Algumas\%20cirurgias\%20s\%C3\%A3o\%20indiferentes $\% 20 \mathrm{de}$, atr $\%$ C3\%A1s\%20de\%20aumento\%20de\%20seios. Último acesso em: 31 mar. 2021. 